\title{
The Role of The Doppler Study (Umbilical, Middle, Cerebral Arteries and Ductus Venosus) to Predict General Adverse Pregnancy Outcomes in Patients With Hypertensive Diseases in The Third Trimester
} Ahmed Majid Salman (MBChB, DMRD) ${ }^{1}$, Mohammed A.K. Al-Jiboori $(\mathrm{MBChB}, \mathrm{FIBM}(\mathrm{Rad}), \mathrm{CABD})^{2}$, Hadeel Qasim Khaleel $(\mathrm{MBChB}, \mathrm{DMRD})^{3}$ and Enas Adnan (MBChB, DOG, FIBM/GO, CABS/GO $)^{4}$

${ }^{1}$ Physician Specialist in Diagnostic Radiology, Al-Batool Teaching Hospital, Diyala, Iraq

${ }^{2}$ Diagnostic Radiology, Medical College,University of AL-Nahrain-Baghdad, Iraq

${ }^{3}$ Physician Specialist in Diagnostic Radiology, Al-Batool Teaching Hospital, Diyala, Iraq

${ }^{4}$ Obstetrics \& Gynecology Medical College,University of AL-Nahrain,Baghdad, Iraq

Correspondence Address:

Ahmed Majid Salman

Department of Medicine, Baquba Teaching Hospital, Diyala, Iraq

email: dr_ahmedmajid@yahoo.com

Received: 23 October 2020

Accepted: 26 September 2021

Published: 25 December 2021

Diyala Journal of Medicine 2021:21(2): 10-21

\section{Abstract}

Background: The hypertensive pregnancies complicated by preeclampsia show an increase in maternal and perinatal morbidity and mortality.Color Doppler ultrasound has been employed for fetal surveillance.

Objective: To evaluate the role of Doppler study in the prediction of adverse pregnancy outcomes in hypertensive pregnant women at the third trimester of pregnancy.

Patients and Methods: A clinical prospective follow up study conducted in Outpatient Ultrasound Clinic at Al-Imamein Kadhimein Medical City, Baghdad, Iraq from $1^{\text {st }}$ July, 2018 till $31^{\text {st }}$ of July 2019 included 50 pregnant women with hypertensive disorder of pregnancy at the third trimester. The fetal and neonatal outcome was reported poor when intrauterine fetal death occurs during follow-up of pregnant women or more than two of the reported neonatal complications were poor.

Results: Means of the middle cerebral artery and umbilical artery-resistance and pulasatility indices ratio were significantly decreased among pregnant women with poor neonatal outcomes. Similarly, the umbilical artery end-diastolic flow and Ductus Venousu waveforms were

Conclusion: The middle cerebral artery and umbilical artery indices of pregnant women with hypertensive disorders are good predictors for neonatal outcomes.

Keywords: Hypertensive disorder, Middle cerebral artery, Umbilical artery, Ductus venosus 


\section{Introduction}

Hypertensive disorders of pregnancy (HDP), including preeclampsia (PE) and gestational hypertension (GHTN), were considered the most common pregnancy medical complications, affecting $6 \%-8 \%$ of pregnant women [1], and they are one element of the deadly triad, along with infection and hemorrhage, which contributes significantly to maternal morbidity and mortality [2].

Decreased uteroplacental blood flow, fetal hypoxemia, and intrauterine growth restriction (IUGR) are proposed hypotheses explaining the increased risks of fetal and infant death associated with pregnancy induced hypertension (PIH). The reduced uteroplacental perfusion was regarded as the primary step of diverse pathogenic processes in the development of PIH [3]. Hypertensive Pregnancies complicated by preeclampsia show an increase in maternal and perinatal morbidity and mortality [4] and intrauterine growth restriction, as revealed by small for gestational age, involves a fair percent of newborn infants world widely, mostly in developing countries [5]. Early prediction of GHTN and PE is essential for arrangement of clinical management strategy and proper monitoring that can lessen the occurrence of complications from these conditions and save medical expenses [6].

Color Doppler ultrasound has been employed for fetal surveillance [7]. Doppler studies are noninvasive and can evaluate abnormal fetal hemodynamics that takes place in response to changes in placental resistance [8]. It can assist to recognize the degree of insufficiency of the placenta and in the detection of the deterioration of the condition, thereby the judgment for intervention can be considered once it is needed[9]. The results of umbilical artery (UA) Doppler is a reflection of the placenta status, whereas the results obtained from a middle cerebral artery (MCA) and aorta indicate the state of fetal circulation [10]. Doppler ultrasound is used in high-risk pregnancies, particularly the cases complicated by fetal growth retardation, preeclampsia, or other maternal medical conditions [11]. Abnormal MCA Doppler alone illustrated limited predictive accuracy to compromise the fetal and neonatal wellbeing [12, 13]. After the 34th week of gestational age, cerebro-placental ratio is not significantly related to the prognosis and outcome of the pregnancy [14]. Therefore, during the 3rd trimester, the ratio of the pulsatile index (PI) and resistance index (RI) of MCA to descending aorta could be used [15]. This is while various studies have shown that, as the gestational age increases, the vascular resistance of descending aorta is kept unchanged [16]. Hence, Doppler indices of this artery could be used for investigation of hemodynamic status, especially after the 34th week of pregnancy [17]. This study was conducted to assess the role of the Doppler study (Middle cerebral artery, Umbilical artery, and ductus venosus) in the prediction 
of adverse pregnancy outcomes in women pregnant having hypertensive disorders at the
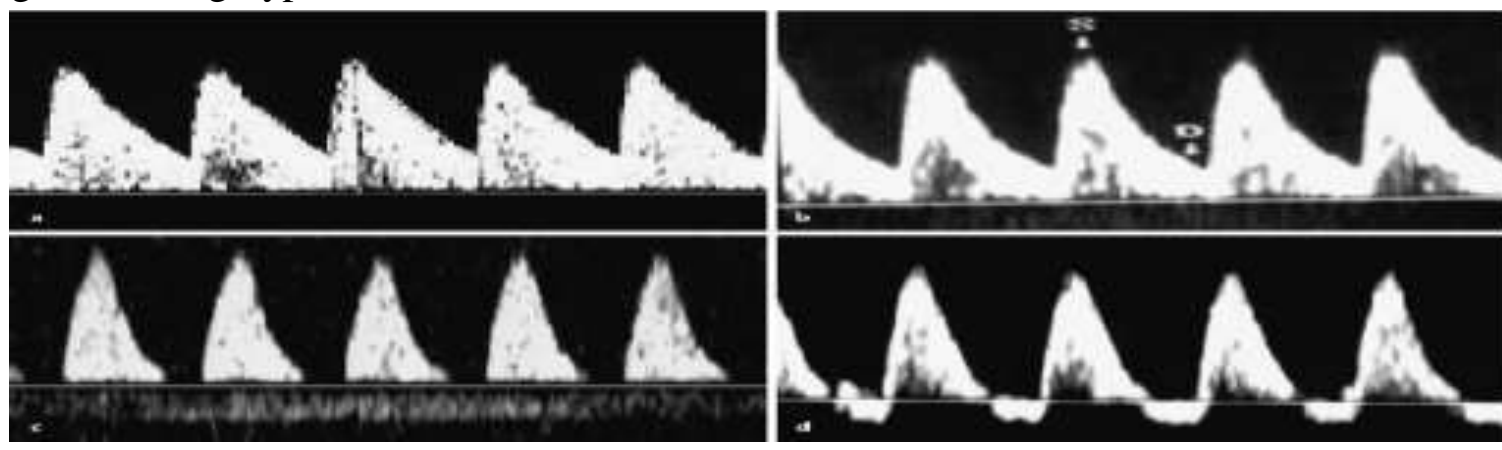

Figure (1): Different flow velocity waveforms of the umbilical artery

(A): Normal end-diastolic flow, (B): Reduced end-diastolic flow, (C): Absent end-diastolic flow (D): Reversed flow

\section{Patients and Methods}

This a prospective follow-up study carried out in outpatient clinics for ultrasound at AlImamein Kadhimein Medical City/ Baghdad/ Iraq during the period of $1^{\text {st }}$ of July 2018 till $31^{\text {th }}$ of July 2019. Ethical approval was taken from the institutional review board of AlNahrain College of Medicine, an verbal informed consent was taken from all women contributing to the study.

Inclusion criteria: pregnant women at $3^{\text {rd }}$ trimester (28- 40 weeks), age (18-41 years), with hypertensive disorder of pregnancy confirmed by obstetricians.

Exclusion criteria: other diseases that interfere with fetal development like diabetes, COPD, thyroid diseases, autoimmune disease, renal diseases,etc., congenital malformations, intrauterine fetal death, loss to follow up and patients refusing to participate in study.

The data was collected directly from pregnant women or from their records and were registered in a self- organized questionnaire. The following information was checked in every participant: general characteristics (age, gravidity, and body mass index, characteristics of hypertensive disorders (categories of hypertensive disorder, control of hypertension and diagnosis delivery interval, investigations findings (general urine examination [albumin in urine], platelets and hemoglobin), ultrasound findings (gestational age, fetal AC, fetal FL, fetal BPD, site of placenta, and AFI), Doppler-Ultrasound findings (MCARI, MCA-PI, MCA-SD, UA-RI, UA-PI, UASD, MCA/UA-RI, MCA/UA-PI and DV waveform), and fetal and neonatal outcome (reported poor when IUFD occurs during follow-up of pregnant women or more than two of the following reported neonatal complications (IUGR: It is synonymous with the term small for gestational age, Low birth weight, Apgar scores less than 7 at 5 minutes, NICU admission and preterm babies).

Ultrasound examination: UA and one MCA were examined for each patient by VolusonE6 Ultrasound machine (GE Healthcare, USA). The entire measurements were achieved in semi recumbent positions with the chest and head were slightly elevated (to minimize the risk of developing supine 
hypotension syndrome due to caval compression). UA measurements were performed in a free umbilical cord loop. Following affirmation of regular maternal and fetal cardiac frequency, without interference with fetal movement and/or fetal breathing, and away from the chest, the waves were registered. The angle of Doppler insonation was situated below $60^{\circ}$.

Spectral waveforms were tested and the recordings were taken for analysis after clearance only, steady-state was get for at least 5 repeated pulsatile arterial waveforms. Measurement of the MCA, the fetal head should be in the transverse plane. An axial view of the brain, including the thalami and the sphenoid bone wings, should be obtained and magnified. Then, the color Doppler used to visualize the circle of Willis, the MCA vessels are found with color Doppler ultrasound overlying the anterior wing of sphenoid bone near the skull base. All measurements were recorded when the volume of the Doppler sample was situated within $1 \mathrm{~cm}$ of the MCA origin. The angle between the direction of blood flow and the ultrasonographic beam was always <30 degrees. Doppler ultrasound indices were calculated according to the followings: Pulsatility index $(\mathrm{PI})=$ Peak systolic velocity - diastolic velocity/ Mean flow velocity, Resistance index (RI) = Peak systolic velocity diastolic velocity/ Peak systolic velocity, Systolic velocity/ Diastolic velocity (S/D) ratio. In MCA, the abnormal finding was determined as individual decreases in RI or PI values and their combinations. Fetal Ductus venosus flow assessment: the fetus should be as still as possible, the probe is perfectly focused so sampling is made where the umbilical vein joins the ductus venosus, a right ventral mid-sagittal view of fetal trunk should be taken and color flow mapping used to reveal the fetal heart, umbilical vein, and ductus venosus, the probe is ideally angled to permit a transverse oblique plane or midsagittal plane during the fetal abdomen, the image should be exaggerated enough for the fetal abdomen and thorax to occupy the whole screen, the sample of Doppler should be small $(0.5-1 \mathrm{~mm})$, the insonation angle should be $30^{\circ}$ or less. On Doppler ultrasound, the flow in the ductus venosus (DV) has a characteristic triphasic waveform where in a normal physiological situation flow should always be in the forward direction (i.e. towards the fetal heart). This triphasic waveform comprises of: $\mathrm{S}$ wave: corresponds to fetal ventricular systolic contraction and is the highest peak, D wave: corresponds to fetal early ventricular diastole and is the second highest peak and A wave: corresponds to fetal atrial contraction and is the lowest point in the wave form albeit still being in the forward direction. In the presence of end-stage hypoxaemia with hypoxic cardiomyopathy, there is a fall in cardiac function and hence rise in central venous pressure results in absent enddiastolic or reverse flow of DV.

All pregnant women were followed up from the time of examinations in the third trimester till delivery and their neonate were followed up during $1^{\text {st }} 28$ days of life. The follow-up was done by phone calling or direct interview and examination.

\section{Statistical analysis}

It was done via using Statistical Package for Social Sciences (SPSS) version 22. Descriptive statistics are presented as 
(mean \pm standard deviation) and frequencies as percentages. Chi square test was used for categorical variables (Fishers exact test was used when the expected variable was less than $20 \%$ of the total variable). An independent two sample t-test was used to compare between two means. ROC curve was used for the prediction of acceptable cutoff values. Level of significance ( $p$-value) set at $\leq 0.05$.

\section{Results}

Fifty pregnant women with hypertensive disorders were included, the mean age of $30.0 \pm 6.5$ years, $38 \%$ were primigravida and $62 \%$ were multigravida. Viable fetuses present in $88 \%$, while dead fetuses and neonates present in $12 \%$. Term neonates represented $70 \%$ while preterm represented $30 \%$. The mean birth weight of neonates was $2451.3 \pm 660.4 \mathrm{~g} ; 58 \%$ of neonates had a low birth weight. Mean Apgar score at 1 minute was $6.2 \pm 1.6 ; 58 \%$ had a low Apgar score. Mean Apgar score at 5 minutes was 7.4 \pm 1.4 ; $22 \%$ had a low Apgar score. Neonatal NICU admission was seen in $56 \%$. Generally, the poor neonatal outcome was shown in $44 \%$ of neonates. Mean MCA-RI, mean MCA-PI, and mean MCA-SD of pregnant women with poor neonatal outcomes were significantly lower than mean MCA-RI and mean MCAPI of pregnant women with the good neonatal outcomes ( $p$ 0.001, <0.001 and <0.001 respectively). Mean UA-RI and mean UA-RI of pregnant women with poor neonatal outcome were significantly higher than that of pregnant women with the good neonatal outcomes ( $p<0.001)$, while mean UA-SD of pregnant women with poor neonatal outcome was not significantly different from UA-SD of pregnant women with the good neonatal outcomes $(p=0.5)$. The mean MCA/UA-RI ratio of (1.33) for pregnant women with good neonatal outcomes was significantly higher than the mean MCA/UA-RI ratio of $(0.86)$ for women with poor neonatal outcome $(\mathrm{p}<0.001)$. The mean MCA/UA-PI ratio of (1.56) for pregnant women with the good neonatal outcomes, was significantly higher than the mean MCA/UA-PI ratio of (0.81) for women with the poor neonatal outcomes $(\mathrm{p}<0.001)$ Table (1).

Table (1): Distribution of Doppler findings according to neonatal outcomes

\begin{tabular}{|c|c|c|c|}
\hline \multirow[t]{2}{*}{ Variable } & Good & Poor & \multirow[t]{2}{*}{$\mathbf{P}$} \\
\hline & Mean \pm SD & Mean \pm SD & \\
\hline MCA-RI & $0.75 \pm 0.04$ & $0.69 \pm 0.06$ & $0.001 *^{S}$ \\
\hline MCA-PI & $1.55 \pm 0.22$ & $1.26 \pm 0.20$ & $<0.001 *^{\mathrm{S}}$ \\
\hline MCA-SD & $4.05 \pm 0.67$ & $2.78 \pm 0.84$ & $<0.001 *^{\mathrm{S}}$ \\
\hline UA-RI & $0.58 \pm 0.08$ & $0.85 \pm 0.17$ & $<0.001 *^{\mathrm{S}}$ \\
\hline UA-PI & $1.02 \pm 0.15$ & $1.84 \pm 0.69$ & $<0.001 *^{S}$ \\
\hline UA-SD & $2.75 \pm 0.32$ & $2.68 \pm 0.18$ & $0.5^{* \mathrm{NS}}$ \\
\hline MCA/UA-RI & $1.33 \pm 0.19$ & $0.86 \pm 0.23$ & $<0.001 *^{S}$ \\
\hline MCA/UA-PI & $1.56 \pm 0.34$ & $0.81 \pm 0.36$ & $<0.001 *^{\mathrm{S}}$ \\
\hline
\end{tabular}

There was a highly significant association between absent or reversed UA end-diastolic flow in hypertensive pregnant women with the poor neonatal outcomes $(\mathrm{p}<0.001)$. All these findings were shown in the Table (2). 
Table (2): Distribution of UAEDF according to neonatal outcomes

\begin{tabular}{|c|c|c|c|c|c|}
\hline \multirow[t]{2}{*}{ Variable } & \multicolumn{2}{|c|}{ Good } & \multicolumn{2}{|c|}{ Poor } & \multirow[t]{2}{*}{ P-value } \\
\hline & No. & $\%$ & No. & $\%$ & \\
\hline \multicolumn{5}{|l|}{ UAEDF } & \multirow[t]{5}{*}{$\left\langle<0.001 *^{S}\right.$} \\
\hline Normal EDF & 18 & $\overline{56.0}$ & 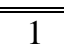 & 2.0 & \\
\hline Decrease EDF & 10 & 20.0 & 9 & $\overline{18.0}$ & \\
\hline Absent EDF & 0 & 0.0 & $\overline{77}$ & $\overline{14.0}$ & \\
\hline Reverse EDF & 0 & 00 & $\overline{5}$ & $\overline{100}$ & \\
\hline
\end{tabular}

There was a highly significant association between absent or decreased Doppler waveforms of DV of pregnant women with hypertensive disorders and poor neonatal outcome $(\mathrm{p}<0.001)$. As shown in the Table (3).

Table (3): Distribution of Doppler-US DV according to neonatal outcome

\begin{tabular}{|c|c|c|c|c|c|}
\hline \multirow[t]{2}{*}{ Variable } & \multicolumn{2}{|c|}{ Good } & \multicolumn{2}{|c|}{ Poor } & \multirow[t]{2}{*}{ P-value } \\
\hline & No. & $\%$ & No. & $\%$ & \\
\hline \multicolumn{5}{|l|}{ DV } & \multirow[t]{5}{*}{$<0.001 * \mathrm{~S}$} \\
\hline Normal & 24 & 85.7 & 4 & 18.2 & \\
\hline Negative & 3 & 10.7 & 11 & 50.0 & \\
\hline Decrease & 1 & 3.6 & 3 & 13.6 & \\
\hline Absent & 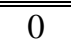 & - & 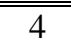 & 18.2 & \\
\hline
\end{tabular}

*Fishers exact test, $\mathrm{S}=$ Significant

Acceptable cut off points and validity values for MCA/UA-RI ratio in prediction of poor neonatal outcome was shown in Table (4) and figure 1a, cutoff poor neonatal outcome level of 1.05 had validity results $(82.1 \%$ sensitivity, $\quad 81.8 \%$ specificity, 80\%PPV, $81.5 \%$ NPV and $80 \%$ accuracy).
The acceptable cut off points and valid values for MCA/UA-PI in the prediction of poor neonatal outcome was shown in Table 4 and Figure 1b, cutoff MCA/UA-PI ratio level of 1.07 had validity results $(82.1 \%$ sensitivity, $77.3 \%$ specificity, $80.6 \%$ PPV, $75.3 \% \mathrm{NPV}$, and $78 \%$ accuracy).

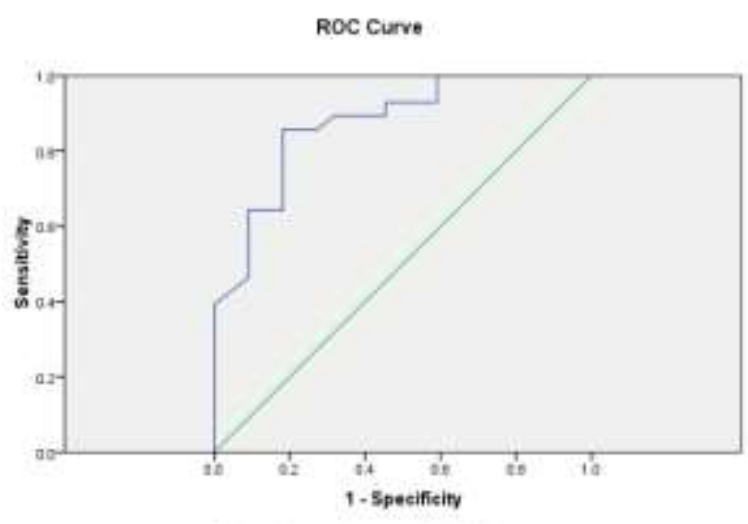

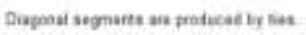

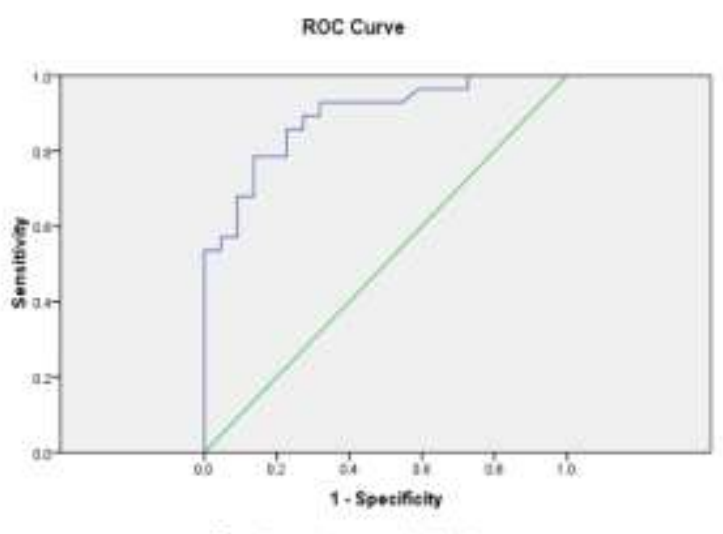

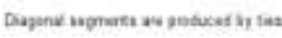

Figure (2a): ROC for MCA/UA-RI ratio, the prediction of poor neonatal outcomes (AUC $=0.87$ ) (2b): ROC for MCA/UA-PI, the prediction of poor neonatal outcomes (AUC=0.89) 
Table (4): ROC coordinates for prediction of poor neonatal outcome by MCA/UA-RI ratio and MCA/UA-PI ratio

\begin{tabular}{|l||c|c|c||c|c|c||}
\hline \multicolumn{1}{|c||}{} & \multicolumn{3}{c|}{ MCA/UA-RI ratio } & \multicolumn{3}{c|}{ MCA/UA-PI ratio } \\
\hline \hline Cutoff point & 0.88 & 1.05 & 1.13 & 1.05 & 1.07 & 1.2 \\
\hline \hline Sensitivity & $89.3 \%$ & $82.1 \%$ & $60.7 \%$ & $89.3 \%$ & $82.1 \%$ & $67.9 \%$ \\
\hline \hline Specificity & $63.6 \%$ & $81.8 \%$ & $90.9 \%$ & $68.2 \%$ & $77.3 \%$ & $90.9 \%$ \\
\hline \hline PPV & $85 \%$ & $80 \%$ & $65.4 \%$ & $88.4 \%$ & $80.6 \%$ & $61.5 \%$ \\
\hline \hline NPV & $62.5 \%$ & $81.5 \%$ & $92 \%$ & $69 \%$ & $75.3 \%$ & $90 \%$ \\
\hline \hline Accuracy & $66 \%$ & $80 \%$ & $75.3 \%$ & $68 \%$ & $78 \%$ & $73 \%$ \\
\hline
\end{tabular}

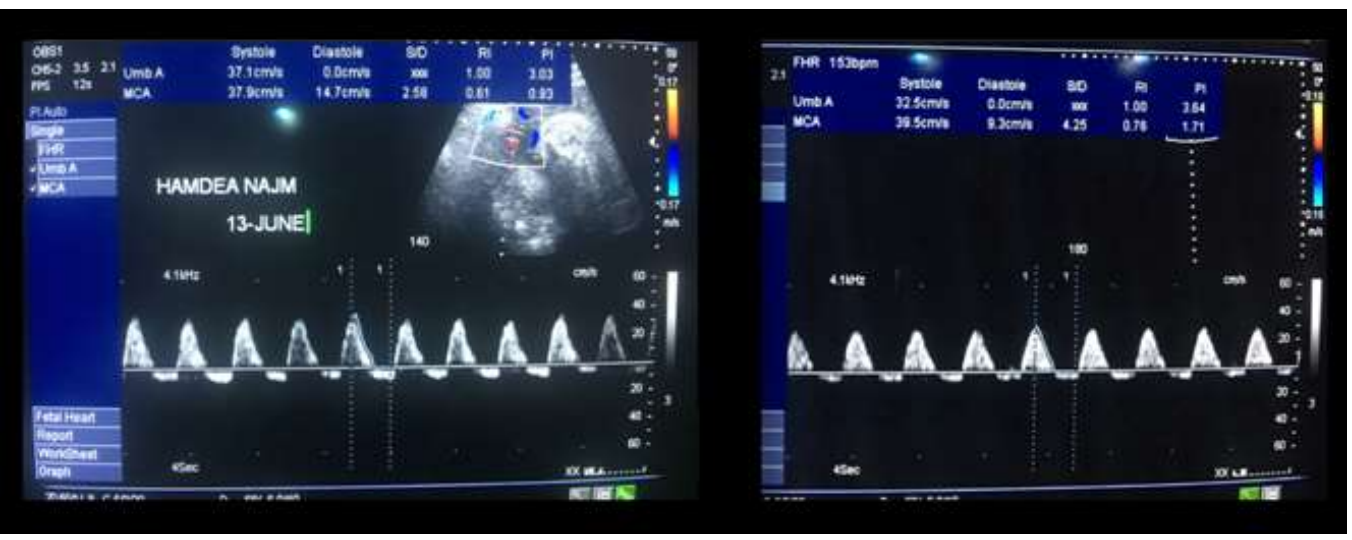

Figure (3): Shows REDF of umbilical artery in two patients with preeclampsia at the third trimester

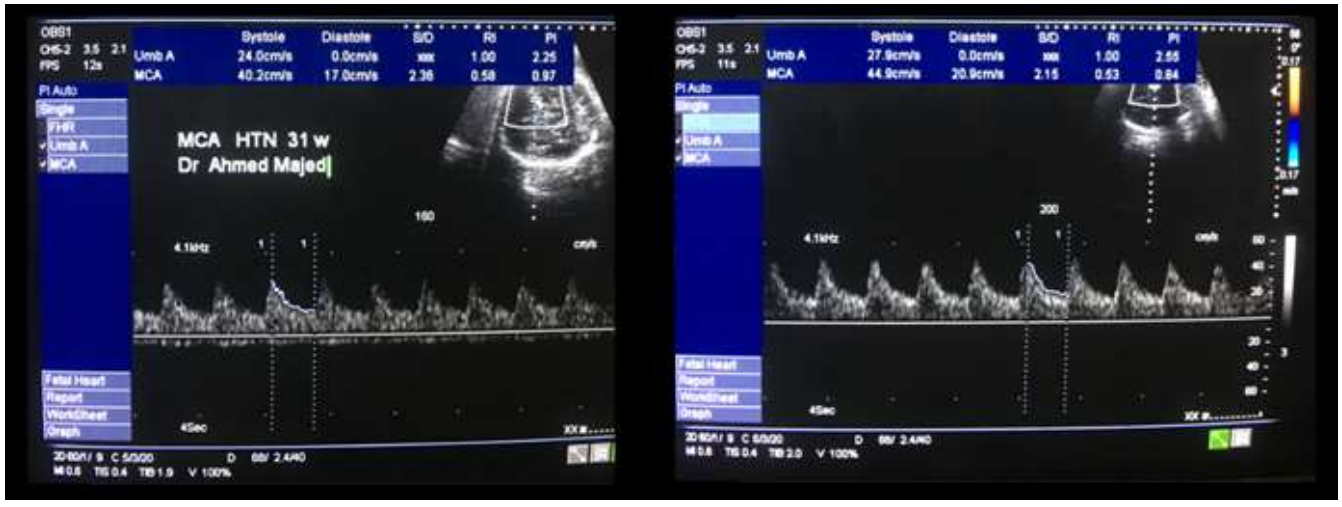

Figure (4): Shows blood redistribution by increase diastolic flow of MCA in two different patients with preeclampsia at third trimester. (Brain sparing phenomena). with RI of 0.56 (left), RI of 0.53 (right) 


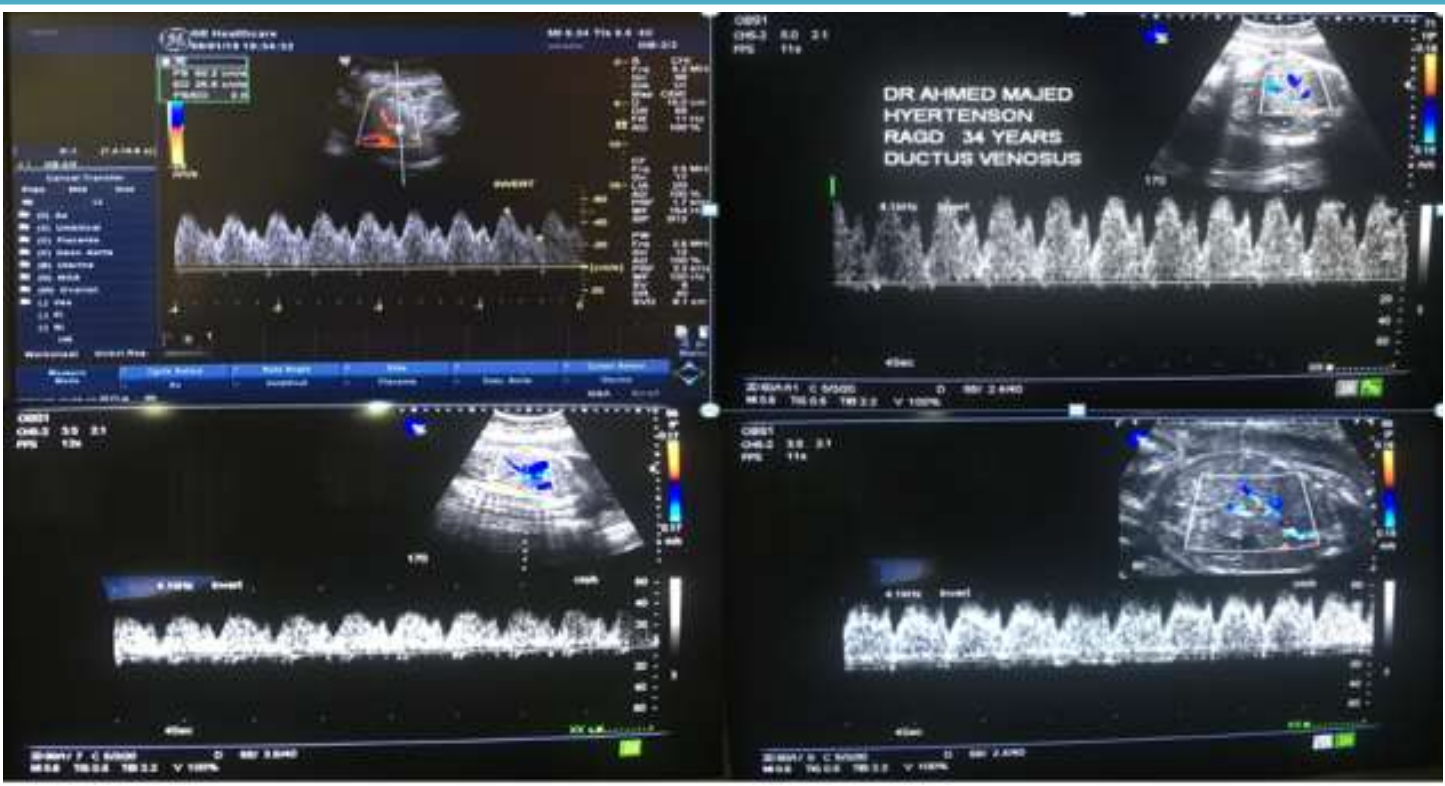

Figure (5): shows normal ductus venosus waveforms in different four patients with HDP at the third trimester

\section{Discussion}

Prediction of neonatal outcomes for pregnant women with hypertensive disorders in pregnancy is essential to reduce neonatal morbidity and mortality. Application of Doppler waveform studies for preeclamptic pregnant women is a useful non-invasive diagnostic technique[18].

In the current study, the mean MCA/UA-RI was (1.12); with a significant difference between pregnant women with good neonatal outcomes (1.33) and with poor neonatal outcomes $(0.86)(<0.001)$. This finding was similar to the results of El Guindy et al [19] study in Egypt which found that cerebroplacental ratio (MCA/UA-RI) is effective Doppler measure in the prediction of poor neonatal outcomes among pregnant women with preeclampsia. The current study showed that ROC curve validity findings for MCA/UA-RI in the prediction of poor neonatal outcomes with a value of less than (1.05) were $(82.1 \%$ sensitivity, $81.8 \%$ specificity, $80 \% \mathrm{PPV}, \quad 81.5 \% \mathrm{NPV}$ and accuracy $80 \%$ ). These findings are better than the results of Arias'study [20] in the USA which reported $57.9 \%$ sensitivity and $75.6 \%$ specificity.

The present study showed a significant difference was observed in MCA/UA-PI ratio between pregnant women with the good neonatal outcome of (1.56) and with the poor neonatal outcomes of $(0.81)(\mathrm{p}<0.001)$. A recent study carried out in India by Kant et al [21] found that $22.8 \%$ of women with high risk pregnancies had MCA/UA-PI ratios of less than one. Padmini et al [18] found that MCA/UA-PI ratio predicted adverse neonatal outcomes is $31.2 \%$. the current study showed that validity results of MCA/UA-PI ratio regarding poor neonatal outcomes by the value of less than (1.07) were $(82.1 \%$ sensitivity, $77.3 \%$ specificity, $80.6 \%$ PPV, $75.3 \%$ NPV, and accuracy 78\%). These findings are better than the results of Shahinaj et al (22) study in Albania which revealed a sensitivity (98\%), specificity $(66 \%)$ and accuracy $(74 \%)$, it was shown that 
Preeclampsia is responsible for about $22 \%$ of neonatal death [23]. Preeclampsia is accompanied with much fetal co-morbidity like preterm labour, underweight, high admission to neonatal intensive care unit in addition to high mortality rates [24]. Another retrospective cohort study conducted in the UK by Khalil et al [25] on 2812 pregnant women in the third trimester found that late pregnancy Doppler MCA/UA index ratio is predictive for stillbirth and neonatal mortality. Lower values of the MCA/UA-PI Doppler ratio were found to be related to bad fetal prognosis. Diastolic flow in cerebral arteries of women with a normal pregnancy is lower than flow in their umbilical arteries regardless of gestational age, for that reason, cerebro-vascular resistance is higher than placental resistance and the MCA/UA ratio is higher than one. Any abnormality inflow to the brain is related to lower MCA/UA ratio of less than one [26]. Shahinaj et al [22]documented lower flow to placenta with the higher flow to the brain, a phenomenon that is called brain sparing effect, which is a reaction for compensation of fetal hypoxia and fetal growth retardation with low umbilical artery $\mathrm{pH}$. However, MCA/UA ratio would decrease progressively, as in the normal fetuses so the hypoxia to be compensated by the brain hyperperfusion [27]. Another study in India conducted by Adiga et al [8], found that MCA/UA ratio had sensitivity (42\%), specificity (87.5\%), and accuracy $(72.6 \%)$ in the prediction of adverse neonatal outcomes among pregnant women with preeclampsia. Nomura et al [28]study in Brazil found that although the strong relationship between neonatal death, and Doppler velocimetry parameters like
MCA, UA and MCA/UA, further analysis showed that preterm birth and obstructed placental circulation were significantly associated with neonatal death. These findings are close to the results of Akolekar et al [29] study in the UK which documented that fetal MCA/UA-PI index ratio is predictive for small for gestational age with sensitivity $62 \%$, specificity $81.7 \%$, and accuracy $75 \%$.

The current study showed that the mean MCA-SD of pregnant women with poor neonatal outcomes was significantly lower than MCA-SD with the good neonatal outcomes $(p<0.001)$. These findings are in agreement with the results of Padmini et al [18] study in India which stated the important role of MCA-SD in the prediction of poor neonatal outcomes among preeclamptic pregnant women.

In the present study, there was a highly significant association between absent or reversed UA end-diastolic flow and poor neonatal outcome $(p<0.001)$. Consistently, a recent study carried out in Nigeria by Adekanmi et al [30] reported that absent or reversed umbilical artery end-diastolic flow is common among preeclamptic pregnant women with poor pregnancy outcome, but they showed that pulsatility index is the better Doppler measurement for prediction of poor pregnancy outcomes. The present study also revealed a highly significant association between absent or decreased DV and poor neonatal outcome $(\mathrm{p}<0.001)$. Similarly, Hidaka et al [31] study in Japan documented that Doppler DV is a valuable diagnostic tool in the prediction of poor neonatal outcomes. The technique of Doppler DV is difficult and needs experienced skills. Yazicioglu et al 
[32] study in Turkey found that Doppler DV at early pregnancy is beneficial in the prediction of preeclampsia at late pregnancy.

This study found a significant association between preterm GA detected by the US and poor neonatal outcomes $(p=0.05)$. This finding coincides with the results of the Backes et al [33] study in the USA which revealed a significant association between prematurity at ultrasound examination and poor neonatal outcomes.

\section{Conclusions}

The MCA and UA indices of pregnant women with hypertensive disorders are good predictors for neonatal outcomes. MCA/UA RI and PI have reliable validity findings in the prediction of neonatal outcomes. The Doppler UA end diastolic flow and Ductus Venosus have valuable role in the prediction of neonatal outcomes. This study recommended adoption of the middle cerebral artery and umbilical artery indices in following pregnant women with preeclampsia.

\section{Acknowledgment}

Great thanks to all medical health staff working in Al- Imamein Kadhimein Medical City for their efforts and help to complete our research.

Source of funding: This research was funded by ourselves and these is no other funding cover this study or manuscript preparation and publication.

Ethical clearance: The approval was taken from Scientific Council of Radiology with an agreement from hospital authorities and the authors helped in management of cases after taking their oral informed consent.

\section{Conflict of interest: Nill}

\section{References}

[1] Hypertension in pregnancy. Report of the American College of Obstetricians and Gynecologists' Task force on hypertension in pregnancy. Obstet Gynecol 2013;122(5):1122-1131.

[2] Sivakumar S, Bhat BV, Badhe BA. Effect of pregnancy induced hypertension on mothers and their babies. Indian $\mathbf{J}$ Pediatr 2007;74(7):623-625.

[3] Chen XK, Wen SW, Smith G, Yang Q, Walker M. Pregnancy-induced hypertension is associated with lower infant mortality in preterm singletons. BJOG 2006;113(5):54451.

[4]World Health Organization. The World Health Report 2018: causes of maternal mortality. WHO 2018.

[5 ] De Onis M, Blössner M, Villar J. Levels and patterns of intrauterine growth retardation in developing countries. Eur $\mathbf{J}$ Clin Nutr 1998;52 Suppl 1:S5-15.

[6] Yang SW, Cho SH, Kang YS, Park SH, Sohn IS, Kwon HS, Hwang HS. Usefulness of uterine artery Doppler velocimetry as a predictor for hypertensive disorders in pregnancy in women with prehypertension before 20 weeks gestation. PLoS One 2019;14(1):e0210566.

[7] Mandruzzato G. Obstetrical Doppler: the evidence today. J Perinat Med 2015;43(2):129-131.

[8] Adiga P, Kantharaja I, Hebbar S, Rai L, Guruvare S, Mundkur A. Predictive value of middle cerebral artery to uterine artery pulsatility index ratio in hypertensive disorders of pregnancy. Int $\mathrm{J}$ Reprod Med 2015;2015:614747.

[9] Rekha BR, Pavanaganga A, Sai Lakshmi MP, Nagarathnamma R. Comparison of 
Doppler findings and neonatal outcome in fetal growth restriction. Int $\mathbf{J}$ Reprod Contracept Obstet Gynecol 2017;6:955-958. [10] Morris RK, Selman TJ, Verma M, Robson SC, Kleijnen J, Khan KS. Systematic review and meta-analysis of the test accuracy of ductus venosus Doppler to predict compromise of fetal/neonatal wellbeing in high risk pregnancies with placental insufficiency. Eur J Obstet Gynecol Reprod Biol 2010;152(1):3-12.

[11] Creasy RK, Resnik R, Iams JD, Lockwood CJ, Moore TR, Greene MF. Maternal-Fetal Medicine. 7th ed. Philadelphia: Elsevier; 2014.

[12] Khalil AA, Morales-Rosello J, Elsaddig M, Khan N, Papageorghiou A, Bhide A, Thilaganathan B. The association between fetal Doppler and admission to neonatal unit at term. Am J Obstet Gynecol 2015;213(1):57.e1-57.e7.

[13]Morales-Roselló J, Khalil A, Morlando M, Bhide A, Papageorghiou A, Thilaganathan B. Poor neonatal acid-base status in term fetuses with low cerebroplacental ratio. Ultrasound Obstet Gynecol 2015;45(2):156-161.

[14]Baschat AA. Arterial and venous Doppler in the diagnosis and management of early onset fetal growth restriction. Early Hum Dev 2005;81(11):877-887.

[15] Eslamian ZL, Zarean E, Moshfeghi M, Heidari Z. Evaluation of the predictive value of fetal Doppler ultrasound for neonatal outcome from the 36th week of pregnancy. $\mathbf{J}$ Res Med Sci 2018;23:13.

[16]Nishihara R, Nakai Y, Tachibana D, Yamamasu S, Iwanaga N, Ishiko O. Effects of different sampling points on evaluation of fetal descending aortic flow. Osaka City Med J 2006;52(1):39-45.

[17]Konje JC, Abrams KR, Taylor DJ. Normative values of Doppler velocimetry of five major fetal arteries as determined by color power angiography. Acta Obstet Gynecol Scand 2005;84(3):230-237.

[18]Padmini CP, Das P, Chaitra RM, Adithya S. Role of Doppler indices of umbilical and middle cerebral artery in prediction of perinatal outcome in preeclampsia. Int $\mathrm{J}$ Reprod Contracept Obstet Gynecol 2016; 5:845-849.

[19] El Guindy AE, Nawara M, ElSanter O. Cerebroplacental ratio and cerebrouterine ratio in predicting neonatal outcome in preeclamptic pregnant Women. Int J Reprod Med Gynecol 2018; 4(1): 022-027.

[20]Arias F. Accuracy of the middlecerebral-to-umbilical-artery resistance index ratio in the prediction of neonatal outcome in patients at high risk for fetal and neonatal complications. Am J Obstet Gynecol 1994;171(6):1541-1545.

[21] Kant A, Seth N, Rastogi D. Comparison of Outcome of Normal and High-Risk Pregnancies Based Upon Cerebroplacental Ratio Assessed by Doppler Studies. J Obstet Gynaecol India 2017;67(3):173-177.

[22] Shahinaj R, Manoku N, Kroi E, Tasha I. The value of the middle cerebral to umbilical artery Doppler ratio in the prediction of neonatal outcome in patient with preeclampsia and gestational hypertension $\mathbf{J}$ Prenat Med. 2010;4(2):17-21.

[23]Arora D, Desai S. Significance of umbilical artery velocimetry in perinatal outcome of growth restricted fetuses 2008; 55(2): 138 . 
[24]Villar J, Carroli G, Wojdyla D, Abalos E, Giordano D, Ba'aqeel H, Farnot U, Bergsjø P, Bakketeig L, Lumbiganon P, Campodónico L, Al-Mazrou Y, Lindheimer M, Kramer M; World Health Organization Antenatal Care Trial Research Group. Preeclampsia, gestational hypertension and intrauterine growth restriction, related or independent conditions? Am J Obstet Gynecol 2006;194(4):921-931.

[25]Khalil A, Morales-Roselló J, Townsend R, Morlando M, Papageorghiou A, Bhide A, Thilaganathan B. Value of third-trimester cerebroplacental ratio and uterine artery Doppler indices as predictors of stillbirth and perinatal loss. Ultrasound Obstet Gynecol 2016;47(1):74-80.

[26] Sibai B, Dekker G, Kupferminc M. Preeclampsia. Lancet. 2005 Feb 26-Mar 4;365(9461):785-799.

[27] Pereira JP Jr, Nielsen-Saines K, Sperling J, Maykin MM, Damasceno L, Cardozo RF, Valle HA, Dutra BRT, Gama HD, Adachi K, Zin AA, Tsui I, Vasconcelos Z, Brasil P, Moreira ME, Gaw SL. Association of prenatal ultrasonographic findings with adverse neonatal outcomes among pregnant women with Zika virus infection in Brazil. JAMA Netw Open 2018;1(8):e186529.

[28] Nomura RM, Niigaki JI, Horigome FT, Francisco RP, Zugaib M. Doppler velocimetry of the fetal middle cerebral artery and other parameters of fetal wellbeing in neonatal survival during pregnancies with placental insufficiency. Rev Assoc Med Bras (1992) 2013;59(4):392-399.

[29] Akolekar R, Sarno L, Wright A, Wright D, Nicolaides KH. Fetal middle cerebral artery and umbilical artery pulsatility index: effects of maternal characteristics and medical history. Ultrasound Obstet Gynecol 2015;45(4):402-408.

[30] Adekanmi AJ, Roberts A, Akinmoladun JA, Adeyinka AO. Uterine and umbilical artery doppler in women with pre-eclampsia and their pregnancy outcomes. Niger Postgrad Med J 2019;26(2):106-112.

[31]Hidaka N, Sato Y, Kido S, Fujita Y, Kato K. Ductus venosus Doppler and the postnatal outcomes of growth restricted fetuses with absent end-diastolic blood flow in the umbilical arteries. Taiwan J Obstet Gynecol. 2017;56(5):642-647.

[32]Yazicioglu HF, Demirbas Ersu R, Dülger Çetin Ö, Çankaya A, Aygün M, Özyurt ON, et al. Ductus venosus Doppler waveform analysis: a new tool for the early prediction of preeclampsia? Ultrasound Obstet Gynecol 2005; 26: 462-462.

[33] Backes CH, Markham K, Moorehead P, Cordero L, Nankervis CA, Giannone PJ. Maternal preeclampsia and neonatal outcomes. J Pregnancy 2011;2011:214365. 